\title{
A Comparative Study on the Positive Lightning Return Stroke Electric Fields in Different Meteorological Conditions
}

\author{
Chin-Leong Wooi, Zulkurnain Abdul-Malek, Behnam Salimi, Noor Azlinda Ahmad, \\ Kamyar Mehranzamir, and Saeed Vahabi-Mashak
}

Institute of High Voltage \& High Current (IVAT), Faculty of Electrical Engineering, Universiti Teknologi Malaysia, 81310 Johor Bahru, Malaysia

Correspondence should be addressed to Zulkurnain Abdul-Malek; zulkurnain@utm.my

Received 29 December 2014; Revised 13 April 2015; Accepted 20 April 2015

Academic Editor: Ismail Gultepe

Copyright ( $(2015$ Chin-Leong Wooi et al. This is an open access article distributed under the Creative Commons Attribution License, which permits unrestricted use, distribution, and reproduction in any medium, provided the original work is properly cited.

\begin{abstract}
Positive cloud-ground lightning is considerably more complex and less studied compared to the negative lightning. This paper aims to measure and characterize the significant parameters of positive return strokes electric field, namely, the zero-to-peak rise time, $10-90 \%$ rise time, slow front duration, fast transition rise time (10-90\%), zero-crossing time, and opposite polarity overshoot relative to peak. To the best of the authors' knowledge, this is the first time such detailed characteristics of positive lightning in Malaysia are thoroughly analyzed. A total of 41 positive lightning flashes containing 48 return strokes were analyzed. The average multiplicity is 1.2 strokes per flash. The majority of positive lightning was initiated from the primary positive charge rather than as a byproduct of in-cloud discharges. The cumulative probability distribution of rise time parameters, opposite polarity overshoot relative to peak, and slow front amplitude relative to peak are presented. A comparison between studies in four countries representing tropic, subtropic, and temperate regions was also carried out. Measured parameters in Florida, Sweden, and Japan are generally lower than those in Malaysia. Positive lightning occurrences in tropical regions should be further studied and analyzed to improve our current understanding on positive return strokes.
\end{abstract}

\section{Introduction}

Lightning flashes can be categorized as either a cloud activity (in-cloud flashes) or a cloud-ground activity (cloud-toground flashes). Depending on the polarity of the initiating charges within a cloud, the cloud-ground (CG) lightning can be generally characterized as either negative or positive return strokes. The CG lightning with positive return strokes transports positive charges from the cloud to ground. A positive lightning occurs because of various cloud charge scenarios such as titled positive dipole, positive monopole, inverted dipole, unusually large positive charge region, negative in-cloud leader channel cut-off, and branching of incloud channel [1].

Lightning strikes the earth more than 100 times each second or 8 million times per day. Previous investigations conducted in different geographical regions confirmed that about $10 \%$ of global CG lightning is positive [2-6]. Malaysia is a tropical country and it lies near the equator. It experiences high lightning and thunderstorm activities with an average of 200 thunder days per year as reported by the Malaysian Meteorological Services [7]. In addition, the data compiled by the National Lightning Detection Network [7, 8] from 2004 to 2011 show that out of a total of 12,392,684 recorded strokes, $2,323,859$ strokes, or $18.75 \%$, were found to be positive return strokes. Despite a relatively significant percentage, positive lightning is considerably less studied than the negative lightning.

Positive lightning discharges are of a great interest to the scientific and engineering communities because of many reasons. When compared to the negative lightning, the positive lightning exhibits higher peak currents (as high as $300 \mathrm{kA}$ ) and delivers more charges to the ground $[3,9,10]$. However, the electromagnetic fields radiated by a positive lightning are also more complex and hence relatively more difficult to be detected. Furthermore, the experimental data on positive 


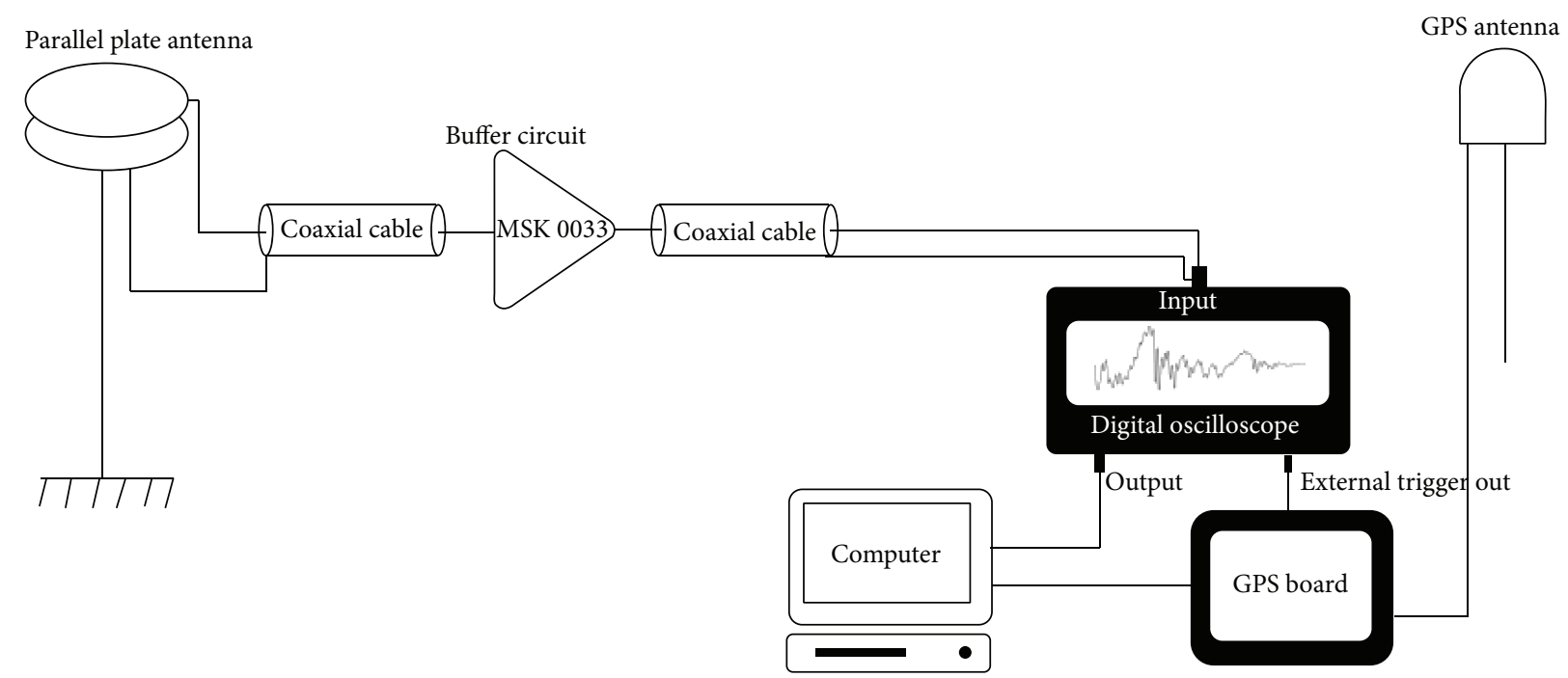

FIGURE 1: Schematic description of the lightning detection system.

lightning are limited and often controversial [6]. Studies have also shown that positive lightning can be associated with the initiation of sprites $[3,9,11,12]$. It is important to study these transient luminous events in the middle and upper atmospheres, as well as to understand their consequential effects on the present lightning protection systems [3]. In addition, studies on directly measured currents from positive flashes are also limited [13-17].

In this study, the vertical component of positive lightning electric field waveforms measured in Malaysia is compared with those obtained in three other countries, namely, Sweden, Japan, and USA. Comparative studies on positive lightning in different meteorological conditions can contribute to better understanding of key characteristics such as the zero-to-peak rise time, $10-90 \%$ rise time, slow front duration, fast transition rise time (10-90\%), zero-crossing time, and opposite polarity overshoot relative to peak [18-21]. It is important to note that the difficulty faced in the characterization of positive lightning is due to the scarcity of positive ground flashes recorded. A significant number of positive return stroke electric fields need to be obtained so that a valid statistical analysis can be carried out. It is also important to determine the influence of different climatic regions on the lightning characteristic. To the best of the authors' knowledge, this study is the first in Malaysia where the data on positive lightning were obtained and thoroughly analyzed. The reported data could add to the current knowledge on positive lightning characteristics especially in a tropical region.

\section{Experimental Setup}

The lightning electric field measurements were performed during the monsoon period (November to February 2012) at the Observatory, Universiti Teknologi Malaysia (UTM), Johor. UTM is located in the southern portion of Peninsular Malaysia which is close to the equator $\left(1.5^{\circ} \mathrm{N}, 103.6^{\circ} \mathrm{E}\right)$.
The average temperature ranges from $25.5^{\circ} \mathrm{C}$ to $27.8^{\circ} \mathrm{C}$, and the average humidity is between $82 \%$ and $86 \%$. The observatory building is located at $142 \mathrm{~m}$ above the sea level.

The configuration of the measuring system used in this study is shown in Figure 1. The setup is similar to those used in several other studies [18, 21-23]. The vertical component of the electric field was captured using $1.5 \mathrm{~m}$ high parallel plate antenna. The antenna was connected to a digital oscilloscope (DSO) (LeCroy WaveRunner 44Xi-A, 8-bit resolution with a sampling rate of $50 \mathrm{MSs}^{-1}$ ) via a buffer circuit. The buffer circuit acts to limit overvoltages and to provide an impedance matching between the antenna and the measuring oscilloscope. The circuit consists of an MSK0033 buffer amplifier, capacitors, and resistors. The input impedance of MSK0033 is $10^{12} \Omega$ which makes it very suitable for the high output impedance antenna. RG58 coaxial cables were used in all connections except for the DSO-PC connection. The oscilloscope was set to $150 \mathrm{~ms}$ pretrigger mode. The decaying time constant of the circuit was set to approximately $10 \mathrm{~ms}$ by changing the RC configuration inside the buffer circuit.

The length of lightning electric field signals captured was set at $500 \mathrm{~ms}$ (including $150 \mathrm{~ms}$ pretrigger time) giving a corresponding file size of $20 \mathrm{MB}$. An instantaneous trigger signal was also sent to a GPS antenna once the oscilloscope was triggered. The GPS antenna was used to synchronize the time. The recorded signals are monitored and analyzed using LabView and Matlab software.

\section{Characteristics and Parameters Analyzed}

Positive lightning parameters such as the zero-to-peak rise time, $10-90 \%$ rise time, slow front duration, slow front relative to peak, fast transition rise time (10-90\%), zerocrossing time, and opposite polarity overshoot relative to peak are analyzed in this section. These data are important for many related applications as described in [24]. 


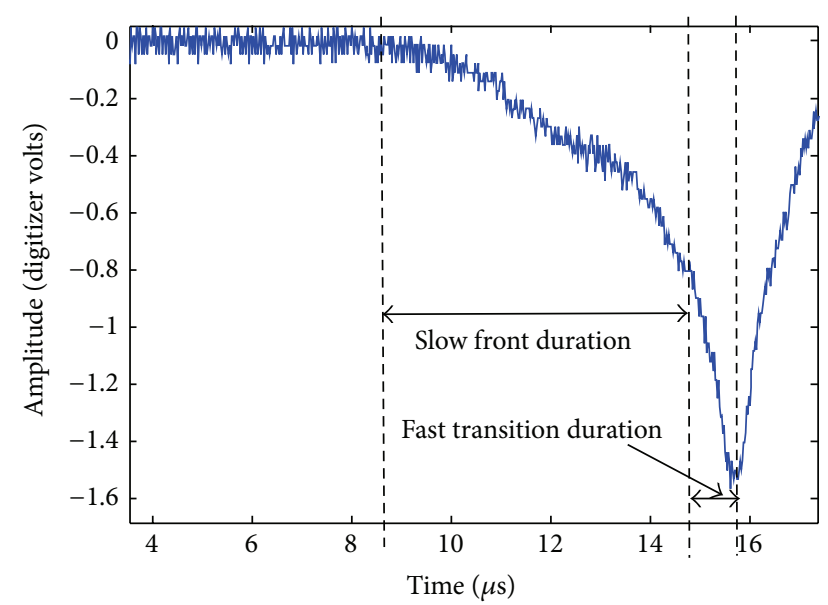

FIGURE 2: Slow front and fast transition sequence in a positive return stroke electric field waveform recorded on November 27, 2012, 3:14:24 pm at UTM observatory.

3.1. Slow Front Duration. The rising part of a return stroke may consist of a slow front stage followed by a fast transition stage. A typical slow front and fast transition sequence in a positive return stroke electric field waveform is shown in Figure 2.

The breakpoints between the slow front and fast transition are usually determined via detailed examination of waveforms on different time scales [9]. In this study, this breakpoint is approximately $50 \%$ of the total peak in first return strokes and is approximately $20 \%$ in subsequent strokes. The existence of a slow front stage in an electric field can be said as a manifestation of a return stroke. The slow front stage is usually followed by a fast transition to peak stage. It is noted that if the slow front duration is long, the fast transition to peak duration is short, and vice versa. Cooray et al. suggested that the longer duration of slow front in positive return strokes is caused by longer streamer portion associated with the positive downward leader [25].

3.2. Zero-Crossing Time, 10-90\% Rise time, and Opposite Polarity Overshoot Relative to Peak. The electric field parameters, namely, the zero-crossing time $\left(\Delta T_{\mathrm{zc}}\right)$, peak amplitude $\left(E_{p}\right)$, opposite polarity overshoot $\left(E_{\mathrm{os}}\right)$, and $10-90 \%$ rise time $\left(\Delta T_{10 / 90}\right)$, are defined in Figure 3.

Zero-crossings can be detected when the return strokes happen at a distance far away from the measuring station [9], typically more than $20 \mathrm{~km}$ away. This is also true for an opposite polarity overshoot where the electric field changes its polarity [26, 27]. Since many zero-crossings and polarity changes were observed in this study, the recorded signals can be said to be dominated by the radiation component of the electric field. This is because the electrostatic and induction field components will only be much larger than the radiation component when lightning occurs approximately $10-12 \mathrm{~km}$ from the measuring station [28]. The $10-90 \%$ rise time is the time between the instants of $E_{10}$ and $E_{90}$ intercepts on the wavefront [29]. This value is used to characterize the fast rising part of the electric field [30].

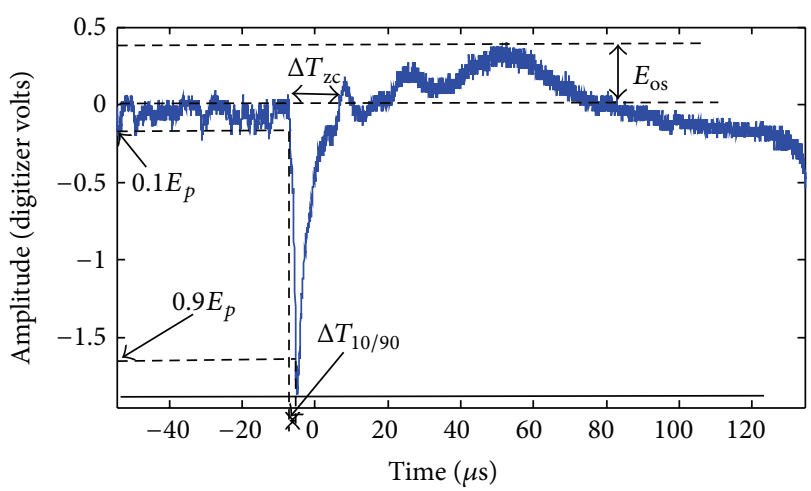

FIgURE 3: Electric field waveform of a positive return stroke on December 6, 2012, 3:48:06 pm defining $\Delta T_{\mathrm{zc}}$ (zero-crossing time), $E_{p}$ (peak amplitude), and $E_{\mathrm{os}}$ (opposite polarity overshoot).

3.3. Cloud Charge Configurations for Positive Lightning. Figure 4 shows the conceptual cloud charge configurations and scenarios leading to production of downward positive lightning [1]. Four charge configurations are described as (a) tilted positive dipole, (b) positive monopole, (c) inverted dipole, and (d) unusually large lower positive charge region. These four charge configurations are responsible for the formation of positive lightning without in-cloud discharge activity. Figures 4(e) and 4(f) show the cloud charge configuration with an in-cloud discharge activity prior to or after a return stroke. The activity is also referred to as lightning channel formation within the cloud. The lightning channel can either be negative in-cloud leader channel (Figure 4(e)) or randomly branched in-cloud channel (Figure 4(f)) [1].

\section{Results and Discussions}

A total of 48 positive return strokes had been successfully identified from 2,289 lightning signals, each with duration of $500 \mathrm{~ms}$. Many signals had to be discarded due to distortions such as signal saturation and signal overlapping. In this study the electric field polarity of positive ground flashes is based on an atmospheric electricity sign convention where the field change due to lowered positive charges is negative.

Table 1 summarizes the analyses on the said signals. A total of 41 samples have all the seven parameters in their characteristics, and 7 samples have one missing parameter, namely, the opposite polarity overshoot.

Figures 5 and 6 show the electric field of a positive return stroke with and without in-cloud activities, respectively. An in-cloud discharge activity is related to the variation in the electric field before and after a return stroke. Thirty out of 48 (63\%) samples recorded in this study do not have in-cloud discharge activity, which means about $63 \%$ of the total cloud configurations are of types (a)-(d) [1]. From this study, it is observed that the majority of positive lightning is initiated from the primary positive charge rather than as a by-product of in-cloud discharges.

4.1. Zero-to-Peak and 10-90\% Rise times. Figure 7 shows the histogram of zero-to-peak rise time which ranges from $1.5 \mu \mathrm{s}$ 


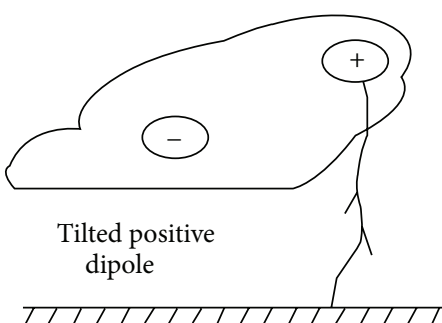

(a)

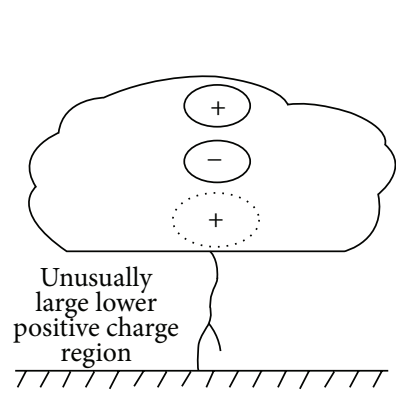

(d)

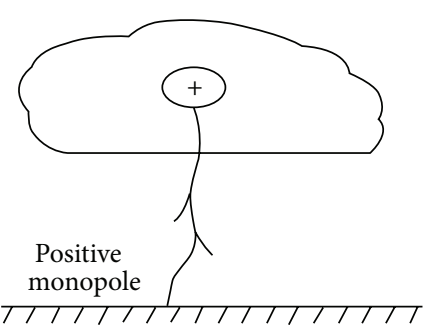

(b)

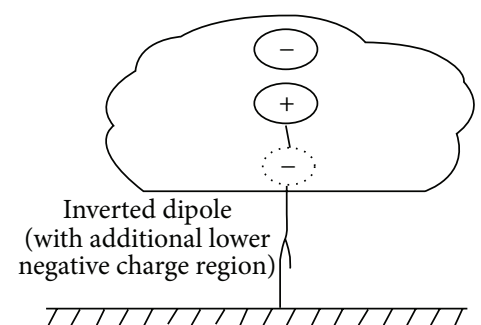

(c)

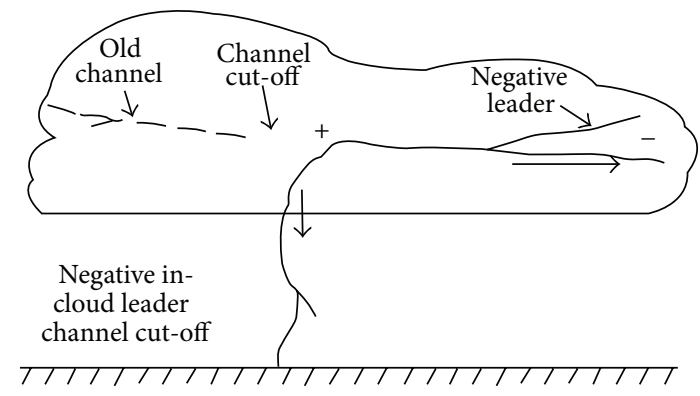

(e)

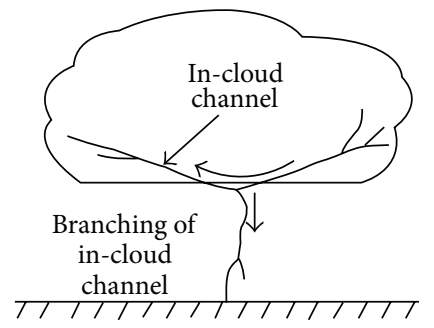

(f)

FIGURE 4: Conceptual cloud charge configurations and scenarios leading to production of downward positive lightning [1].

TABLE 1: The statistical summary of the electric field parameters produced by positive lightning first and subsequent strokes as recorded at UTM observatory building.

\begin{tabular}{|c|c|c|c|c|c|c|}
\hline Parameters & Sample size, $N$ & $\mathrm{AM}$ & $\mathrm{SD}$ & GM & Min & Max \\
\hline Zero-to-peak, $\mu$ s & 48 & 22.4 & 28.1 & 12.9 & 1.5 & 136.9 \\
\hline $10-90 \%$ rise time, $\mu \mathrm{s}$ & 48 & 9.4 & 13.2 & 5.1 & 0.7 & 82.6 \\
\hline Slow front duration, $\mu \mathrm{s}$ & 48 & 19.1 & 25.7 & 9.8 & 0.5 & 131.4 \\
\hline Slow front amplitude relative to peak, $\%$ & 48 & 44.3 & 15 & 41.7 & 17.6 & 76.8 \\
\hline Fast transition $10-90 \%$ rise time, $\mu \mathrm{s}$ & 48 & 2.6 & 4.3 & 1.6 & 0.3 & 28.9 \\
\hline Zero-crossing time, $\mu \mathrm{s}$ & 48 & 57.8 & 140.3 & 23.4 & 2.6 & 834.6 \\
\hline Opposite polarity overshoot relative to peak, \% & 41 & 44.8 & 27.2 & 35.3 & 3 & 104.9 \\
\hline
\end{tabular}

TABLE 2: Statistical summary of zero-to-peak rise time for 48 positive return strokes.

\begin{tabular}{lccc}
\hline & $\begin{array}{c}\text { First return } \\
\text { stroke }\end{array}$ & $\begin{array}{c}\text { Subsequent } \\
\text { return strokes }\end{array}$ & All \\
\hline $\mathrm{AM}, \mu \mathrm{s}$ & 22.4 & 24.9 & 22.4 \\
$\mathrm{SD}, \mu \mathrm{s}$ & 28.1 & 26.3 & 28.1 \\
$\mathrm{GM}, \mu \mathrm{s}$ & 12.9 & 16.9 & 12.9 \\
$\mathrm{Min}, \mu \mathrm{s}$ & 1.5 & 3.1 & 1.5 \\
Max, $\mu \mathrm{s}$ & 136.9 & 91.2 & 136.9 \\
Sample size, $N$ & 39 & 9 & 48 \\
\hline
\end{tabular}

to $136.9 \mu \mathrm{s}$. The arithmetic mean (AM) and geometric mean (GM) are $22.4 \mu \mathrm{s}$ and $12.9 \mu \mathrm{s}$, respectively. The zero-to-peak rise time for subsequent strokes lies within the range of 3.1 to $91.2 \mu \mathrm{s}$. Table 2 shows the summary of zero-to-peak rise time. The figures shown are of AM, GM, minimum (Min), and maximum (Max) values for the first stroke, subsequent strokes, and overall for the data obtained between November
TABLE 3: Statistical summary of $10-90 \%$ rise time for 48 positive return strokes.

\begin{tabular}{lccc}
\hline & $\begin{array}{c}\text { First return } \\
\text { stroke }\end{array}$ & $\begin{array}{c}\text { Subsequent } \\
\text { return strokes }\end{array}$ & All \\
\hline $\mathrm{AM}$ & 9.6 & 8.2 & 9.4 \\
$\mathrm{SD}$ & 14.5 & 5.6 & 13.2 \\
$\mathrm{GM}$ & 4.9 & 6.6 & 5.1 \\
$\mathrm{Min}$ & 0.7 & 1.7 & 0.7 \\
Max & 82.6 & 17.5 & 82.6 \\
Sample size, $N$ & 39 & 9 & 48 \\
\hline
\end{tabular}

2012 and December 2012. The AM for the first stroke is smaller than that of the subsequent strokes.

Figure 8 shows the histograms of the $10-90 \%$ rise time which ranges from $0.7 \mu$ s to $82.6 \mu$ s. The AM and GM are $9.4 \mu \mathrm{s}$ and $5.1 \mu \mathrm{s}$, respectively. Table 3 shows the summary of the analysis for the $10-90 \%$ rise time. Generally, the first return stroke has a longer $10-90 \%$ rise time than that for the subsequent return strokes. 


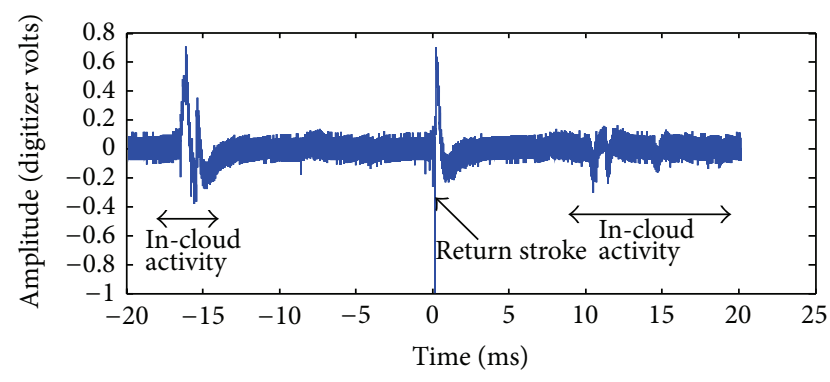

FIgURE 5: An example of electric field record of positive return stroke on November 23, 2012, 4:16:03 pm with both preceding and following in-cloud activities.

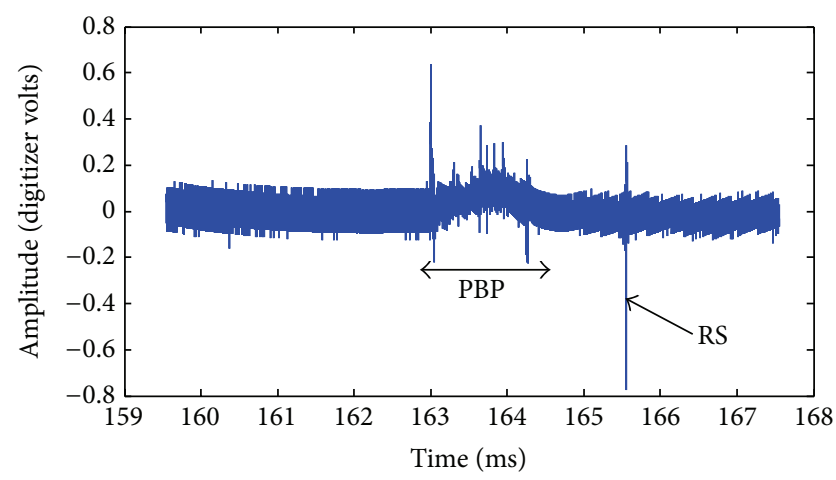

FIGURE 6: An example of electric field record of a positive cloudto-ground flash happenning on 6 December 3:40:05 pm with no incloud discharge activity.

4.2. Slow Front and Fast Transition Parameters. The slow front duration falls within the $0.5 \mu$ s to $131.4 \mu$ s range. The AM and GM values are $19.1 \mu$ s and $9.8 \mu$ s, respectively. The breakpoint between the slow front and fast transition is approximately at $50 \%$ of the peak for the first return stroke and at approximately $20 \%$ of the peak in subsequent strokes. Figure 9 shows the histograms of (a) slow front duration, (b) slow front amplitude relative to peak, and (c) fast transition rise time (10-90\%). The slow front amplitude relative to peak is $44 \%$ (with a range of $18 \%-74 \%$ and a GM of $42 \%$ ). The fast transition rise time (10-90\%) varies from 0.3 to $28.9 \mu$ s with $\mathrm{AM}$ and $\mathrm{GM}$ of $2.6 \mu \mathrm{s}$ and $1.6 \mu \mathrm{s}$, respectively.

Table 4 shows the slow front duration (a), the slow front amplitude relative to peak (b), and the fast transition rise time (10-90\%) (c). It can be seen that the slow front duration and fast transition rise time have larger values for subsequent strokes compared to that for the first stroke. In contrast, the slow front amplitude relative to peak shows that the first stroke has a larger magnitude than that for subsequent strokes.

4.3. Zero-Crossing Time and Opposite Polarity Overshoot Relative to Peak. Figures 10 and 11 show the histograms of zerocrossing time and percentage opposite polarity overshoot relative to peak, respectively. The zero-crossing time ranges from $2.6 \mu$ s to $834.6 \mu$ s as shown in Table 5. The AM and GM values of the zero-crossing time are $57.8 \mu \mathrm{s}$ and $23.4 \mu \mathrm{s}$,
TABLE 4: Statistics for (a) slow front duration, (b) slow front amplitude relative to peak, and (c) fast transition rise time (10-90\%).

(a)

\begin{tabular}{lccc}
\hline & $\begin{array}{c}\text { First return } \\
\text { stroke }\end{array}$ & $\begin{array}{c}\text { Subsequent } \\
\text { return strokes }\end{array}$ & All \\
\hline $\mathrm{AM}, \mu \mathrm{s}$ & 19.1 & 21.1 & 19.1 \\
$\mathrm{SD}, \mu \mathrm{s}$ & 26.2 & 24.9 & 25.7 \\
$\mathrm{GM}, \mu \mathrm{s}$ & 9.8 & 12.5 & 9.8 \\
Min, $\mu \mathrm{s}$ & 0.5 & 1.6 & 0.5 \\
Max, $\mu \mathrm{s}$ & 131.4 & 83.5 & 131.4 \\
Sample size, $N$ & 39 & 9 & 48 \\
\hline
\end{tabular}

(b)

\begin{tabular}{lccc}
\hline & $\begin{array}{c}\text { First return } \\
\text { stroke }\end{array}$ & $\begin{array}{c}\text { Subsequent } \\
\text { return strokes }\end{array}$ & All \\
\hline AM, \% & 44.5 & 43.2 & 44.3 \\
SD, \% & 13.7 & 20.6 & 15 \\
GM, \% & 42.2 & 39.3 & 41.7 \\
Min, \% & 17.6 & 26 & 17.6 \\
Max, \% & 73.9 & 76.8 & 76.8 \\
Sample size, $N$ & 39 & 9 & 48 \\
\hline
\end{tabular}

(c)

\begin{tabular}{lccc}
\hline & $\begin{array}{c}\text { First return } \\
\text { stroke }\end{array}$ & $\begin{array}{c}\text { Subsequent } \\
\text { return strokes }\end{array}$ & All \\
\hline $\mathrm{AM}, \mu \mathrm{s}$ & 2.5 & 3 & 2.6 \\
$\mathrm{SD}, \mu \mathrm{s}$ & 4.7 & 1.7 & 4.3 \\
$\mathrm{GM}, \mu \mathrm{s}$ & 1.4 & 2.5 & 1.6 \\
$\mathrm{Min}, \mu \mathrm{s}$ & 0.3 & 1.1 & 0.3 \\
Max, $\mu \mathrm{s}$ & 28.9 & 6.2 & 28.9 \\
Sample size, $N$ & 39 & 9 & 48 \\
\hline
\end{tabular}

TABLE 5: Statistical summary of zero-crossing time.

\begin{tabular}{lccc}
\hline & $\begin{array}{c}\text { First return } \\
\text { stroke }\end{array}$ & $\begin{array}{c}\text { Subsequent } \\
\text { return strokes }\end{array}$ & All \\
\hline AM & 62.9 & 35.9 & 57.8 \\
SD & 155.1 & 26.1 & 140.3 \\
GM & 22.2 & 28.9 & 23.4 \\
Min & 2.6 & 11.8 & 2.6 \\
Max & 834.6 & 93.7 & 834.6 \\
Sample size, $N$ & 39 & 9 & 48 \\
\hline
\end{tabular}

respectively. Table 5 shows the statistics of zero-crossing time for 48 positive return strokes.

The opposite polarity overshoot relative to the return stroke peak has an average of $45 \%$ (values ranging from 3 to $105 \%$, and a GM of $35 \%$ ). Table 6 shows the statistics of the opposite polarity overshoot relative to the peak for 48 positive return strokes. The zero-crossing time for subsequent strokes tends to be shorter than that for the first return stroke. On the other hand, the opposite polarity overshoot relative to peak tends to be larger than that for the subsequent stroke 
TABLE 6: Statistical summary of opposite polarity overshoot relative to peak.

\begin{tabular}{lccc}
\hline & $\begin{array}{c}\text { First return } \\
\text { stroke }\end{array}$ & $\begin{array}{c}\text { Subsequent } \\
\text { return strokes }\end{array}$ & All \\
\hline AM, \% & 43.4 & 50.8 & 44.8 \\
SD, \% & 26.6 & 30.4 & 27.2 \\
GM, \% & 34.2 & 39.8 & 35.3 \\
Min, \% & 3 & 10.6 & 3 \\
Max, \% & 104.9 & 88.5 & 104.9 \\
Sample size, $N$ & 33 & 8 & 41 \\
\hline
\end{tabular}

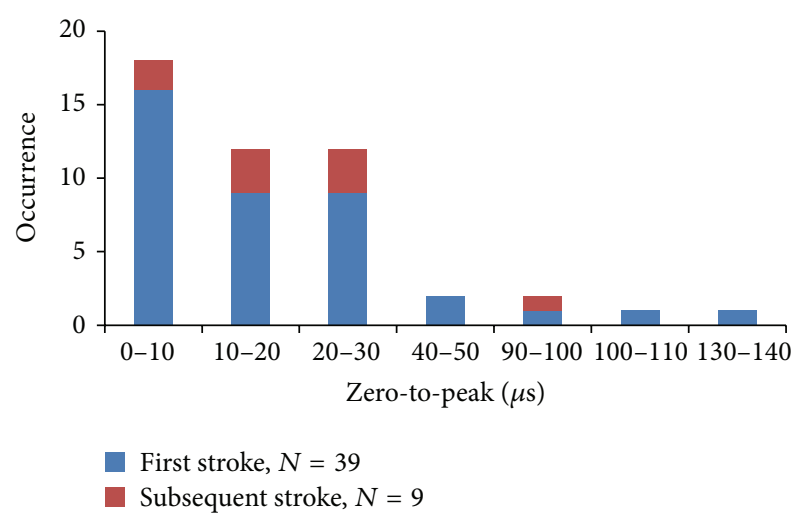

Figure 7: Histograms of zero-to-peak rise time for 48 positive return strokes.

and this is similar to the one reported by [9]. Furthermore, the opposite polarity overshoot relative to peak in subsequent strokes shows a larger value compared to that for the first stroke. It is noted that the positive lightning subsequent stroke signals need to be further investigated since the sample size in this study is rather small for any conclusive observation.

4.4. Cumulative Probability Distribution. The cumulative probability distribution of the positive return stroke's rise times is shown in Figure 12. It is clear that $60 \%$ of the zero-topeak rise time and the slow front duration are within $40 \mu \mathrm{s}$. It can also be infered that the curve for the zero-to-peak rise time is almost similar with that for the slow front duration. This shows that the slow front duration is the dominant component in the zero-to-peak rise time, as explained by [25]. In addition, $70 \%$ of the $10-90 \%$ rise time are actually less than $20 \mu \mathrm{s}$. The fast transition of return strokes usually happens within a short period. Thus, more than $90 \%$ of the fast transition rise time (10-90\%) are less than $10 \mu \mathrm{s}$. The zerocrossing time was not included in this cumulative probability distribution since its duration is much larger than all rise time parameters.

Figure 13 shows the cumulative probability distribution of the percentage of the slow front and the opposite polarity overshoot relative to peak. The slow front amplitude relative to peak varies from $18 \%$ to $77 \%$. It can be infered that

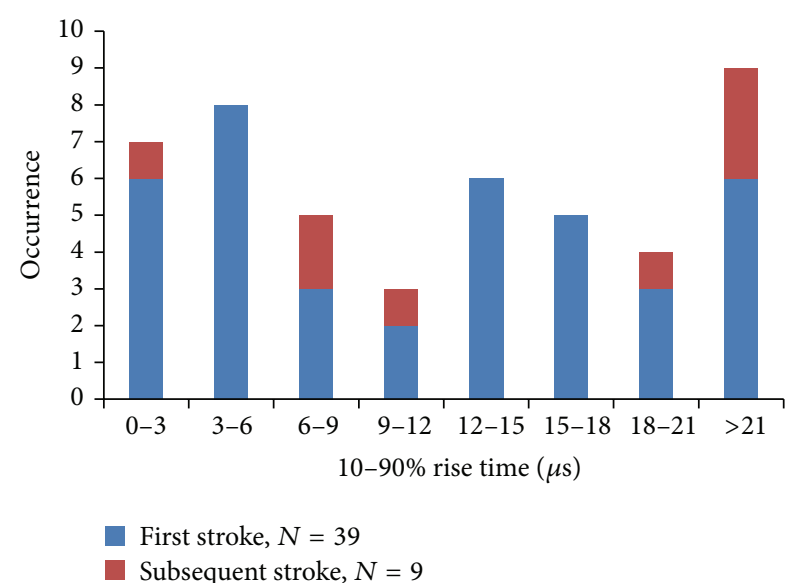

FIGURE 8: Histograms of $10-90 \%$ rise time for 48 positive return strokes.

the electric field amplitude of positive lightning may be influenced by the slow front duration and the fast transition rise times. The opposite polarity overshoot relative to peak varies from $3 \%$ to $105 \%$. It is noted that the magnitude of the opposite polarity overshoot relative to peak can somehow indirectly indicate the distance of the return stroke from the measuring sensor $[26,27]$.

\subsection{Multiplicity and Interstroke Intervals of Positive Lightning}

4.5.1. Multiplicity. Multiplicity is used to denote the number of strokes per flash. Since photographic data is not available, it is possible that some of the subsequent strokes follow a channel different from that for the first return stroke. In this study, positive return strokes that had been recorded in the same $500 \mathrm{~ms}$ window were considered as return strokes from one flash, as per definition in [1]. Multiple strokes may occur in positive flashes but they are rare compared to the negative flashes [11, 31, 32].

Out of 41 flashes analyzed in this study, 5 flashes (12\%) are positive multiple stroke flashes. Out of the five flashes, three had two strokes, one had three strokes, and another one had four strokes. Another 36 flashes (88\%) are positive single stroke flashes. The ratio of the single-stroke to multiple stroke flashes is about $7.2: 1$.

4.5.2. Interstroke Intervals. An interstroke interval is defined as the duration between two consecutive strokes. The distribution of interstroke intervals (8 stroke intervals from 5 positive flashes) is shown in Figure 14. The arithmetic and geometric means of the interstroke interval are $68 \mathrm{~ms}$ and $28 \mathrm{~ms}$, respectively. The minimum and maximum interstroke intervals are $3 \mathrm{~ms}$ and $322 \mathrm{~ms}$, respectively. The average number of strokes per flash is 1.2 , which is comparable with those from other regions, namely, Germany (1.1-1.3) [33, 34], Brazil (1.0) [11], and United States (1.0-1.2) [1,35]. However, it is slightly lower compared to that in Sweden (1.5) [17]. 


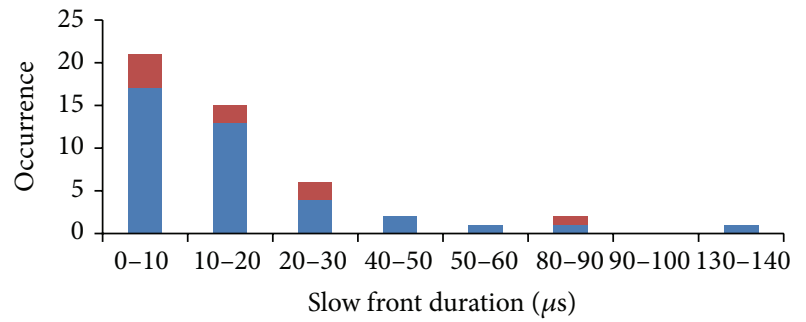

First stroke, $N=39$

Subsequent stroke, $N=9$

(a)

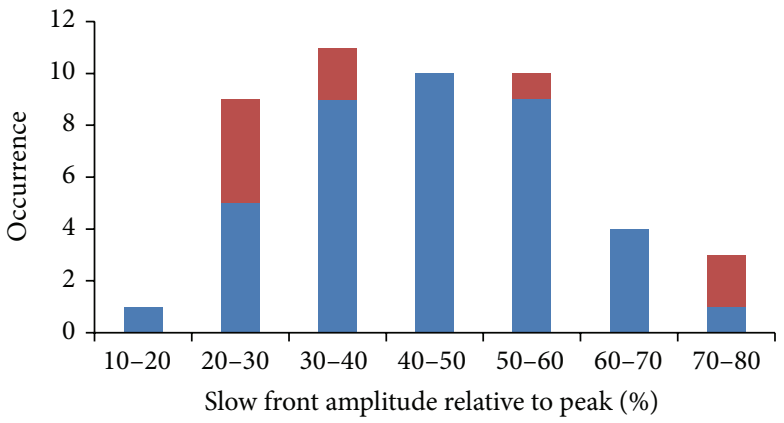

First stroke, $N=39$

Subsequent stroke, $N=9$

(b)

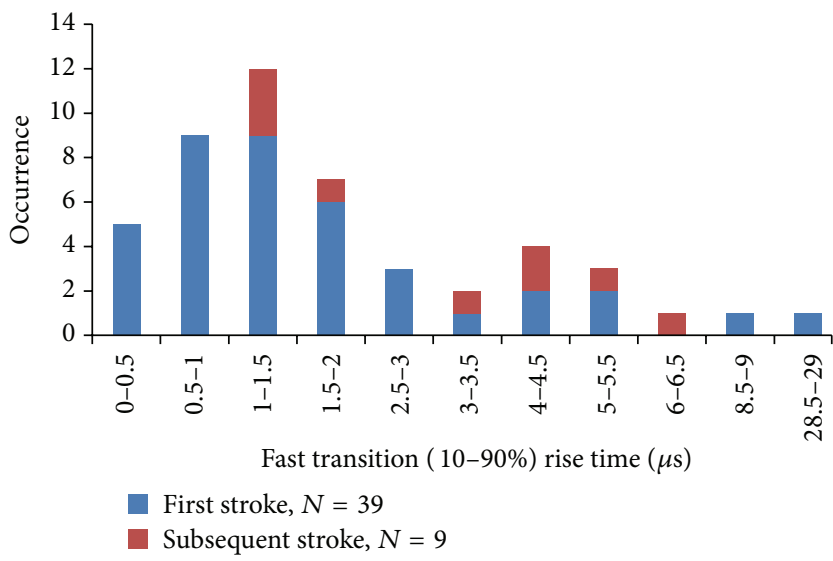

(c)

Figure 9: Histograms of (a) slow front duration, (b) slow front amplitude relative to peak, and (c) fast transition rise time (10-90\%).

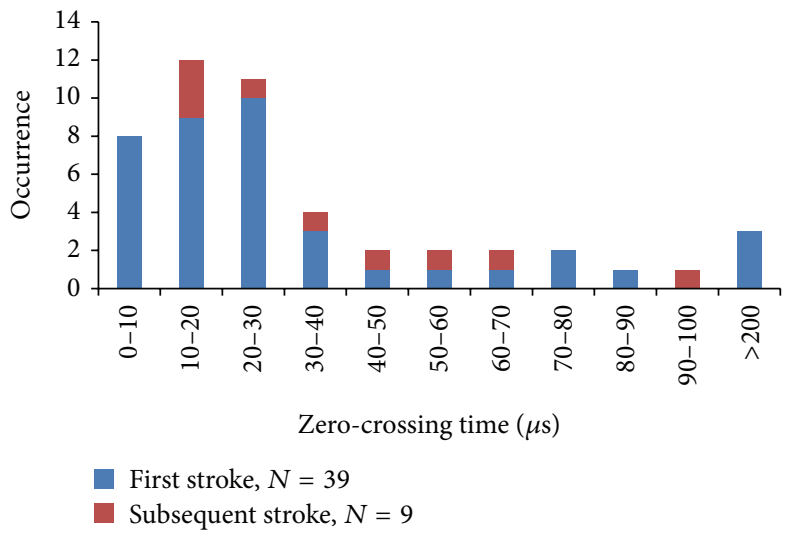

FIGURE 10: Histograms of zero-crossing time for 48 positive return strokes.

\section{Comparison with Other Data}

The characteristics of lightning are known to be dependent on the geographical region (the latitude) as well as the storm type. The results of this work are compared with those in other geographical and climatic regions. Such comparison

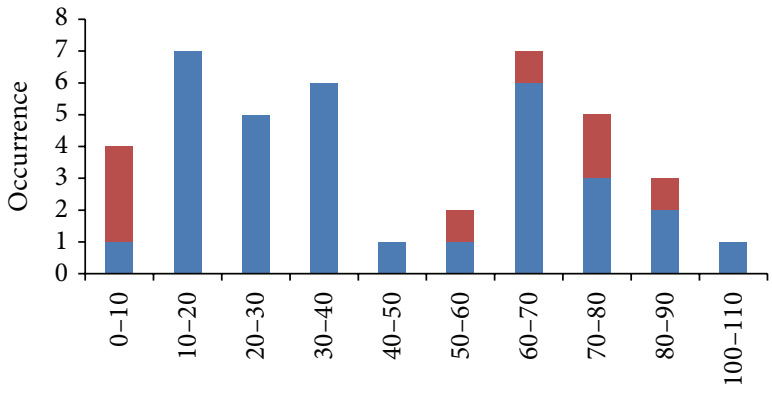

Opposite polarity overshoot relative to peak (\%)

First stroke, $N=33$

- Subsequent stroke, $N=8$

FIGURE 11: Histograms of opposite polarity overshoot relative to peak for 48 positive return strokes.

can add to the current knowledge on lightning characteristics and can indirectly minimize the lightning-related accidents and damages, particularly in tropical regions. Table 7 shows the overall comparison made with the reports from studies published by various authors, namely, Rust et al. (1981) [36], Cooray and Lundquist (1982) [2], Beasley et al. (1983) [37], 


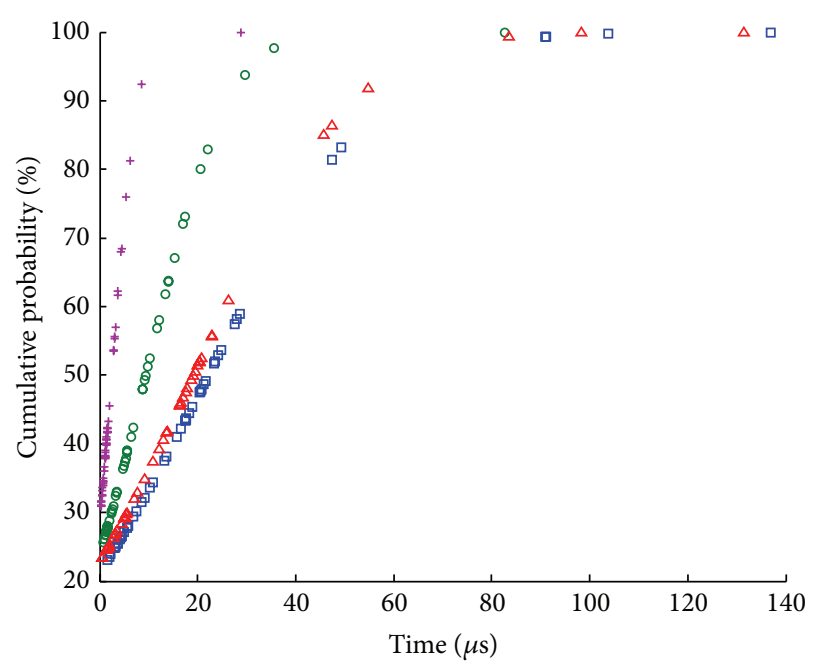

$\begin{array}{ll}\square \text { Zero-to-peak rise time } & \Delta \text { Slow front duration } \\ \circ 10 \text {-to- } 90 \% \text { rise time } & + \text { Fast transition } 10 \text {-to- } 90 \% \text { rise time }\end{array}$

FIGURE 12: Cumulative probability distribution of various rise time parameters.

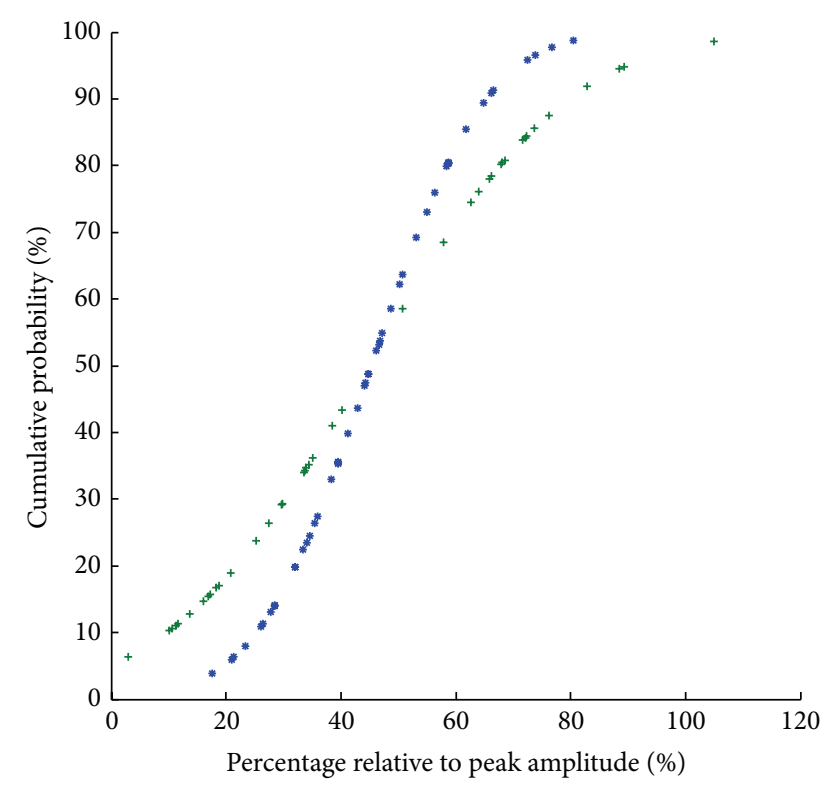

* Slow front amplitude relative to peak

+ Opposite polarity overshoot relative to peak

FIGURE 13: Cumulative probability distribution of the slow front amplitude and the opposite polarity overshoot relative to peak.

Hojo et al. (1985) [38], Cooray (1986) [39], Ishii and Hojo (1989) [40], Cooray (2004) [25], and Nag and Rakov (2014) [9]. Table 8 shows the comparative values of key parameters from selected studies based on climatic regions, in per unit values where the measured values in Malaysia are made as bases.

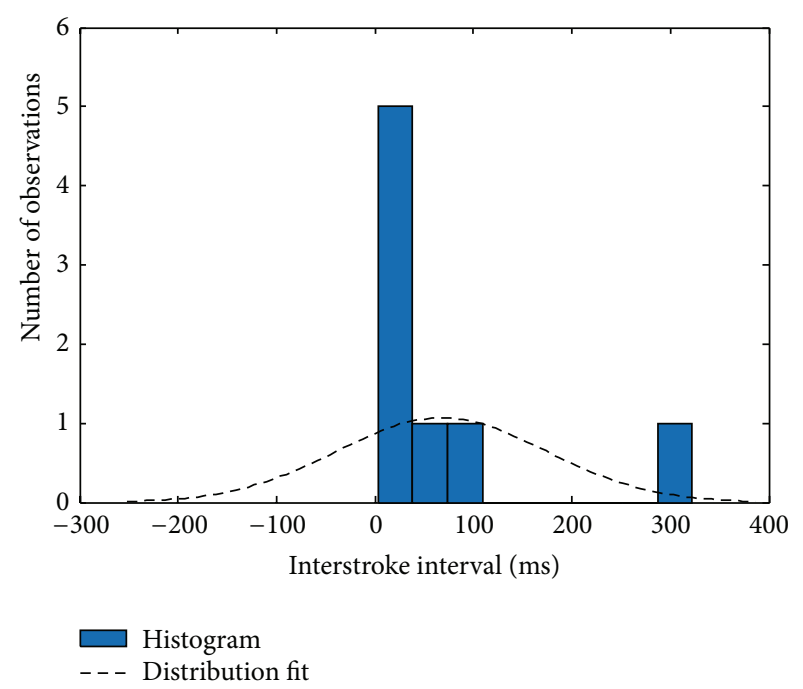

FIGURE 14: Distribution of the interstroke interval for positive ground flashes.

5.1. Zero-to-Peak and 10-90\% Rise times. The zero-to-peak rise time obtained in this study is similar to those reported by Ishii and Hojo [40] for 123 positive return strokes recorded in winter. However, the value is $50 \%$ larger than that reported by the same authors in summer. The zero-to-peak rise time seems to be dependent on the geographical region as well as the season during which measurements were made. For example, the AM of zero-to-peak rise time in Florida [9] for positive return strokes in summer and winter were $7.5 \mu \mathrm{s}$ and $8.5 \mu \mathrm{s}$, respectively, giving an average zero-to-peak rise time of $7.8 \mu \mathrm{s}$. On the other hand, the AM of zero-to-peak rise time in Sweden [2] for positive return strokes is $13 \mu$ s (summer data only). In general, summer lightning tends to have shorter rise times when compared to winter lightning due to different cloud charge configurations.

Both zero-to-peak and $10-90 \%$ rise times reported in temperate countries such as Sweden and Japan, and in subtropical countries such as Florida, are generally smaller compared to that in this study. This could be due to the fact that the height of the thundercloud base in tropical regions is higher than that in temperate regions [16].

5.2. Slow Front and Fast Transition Parameters. The slow front duration and the slow front amplitude relative to peak for the same geographical condition may vary depending on the wave propagation media, such as soil, sea water, and etcetera. For example, Cooray and Lundquist [2] reported that the AM of slow front duration for the data measured in Sweden is $10 \mu \mathrm{s}$. Also, Cooray [39] reported an average slow front duration of $8.2 \mu \mathrm{s}$ for 20 positive return strokes measured $200 \mathrm{~m}$ from seawall. The average magnitudes of the slow front duration reported in Japan, Sweden, and Florida are 0.7, 0.4, and 0.3 p.u. of that obtained from this study (1.0 p.u.), respectively. The slow front relative to peak obtained in Malaysia is slightly larger than that for Florida and is 1.4 times smaller than that in Sweden. The average 
TABLE 7: Statistics of different parameters of positive return stroke electric fields obtained in different studies.

\begin{tabular}{|c|c|c|c|c|}
\hline & Sample size, $N$ & $\mathrm{AM}$ & SD & GM \\
\hline \multicolumn{5}{|c|}{ Zero-to-peak rise time, $\mu \mathrm{s}$} \\
\hline Rust et al. (1981) [36] & 15 & 6.9 & - & - \\
\hline \multirow[t]{2}{*}{ Cooray and Lundquist (1982) [2] } & 64 & 13 & 4 & - \\
\hline & 52 & 12 & 3 & - \\
\hline \multirow[t]{2}{*}{ Ishii and Hojo (1989) [40] } & 32 & 13.2 & 3.6 & - \\
\hline & 123 & 21.2 & 5.8 & - \\
\hline \multirow[t]{2}{*}{ Cooray (1986) [39] } & 20 & 8.9 & 1.7 & - \\
\hline & 62 & 7.8 & 3.8 & 6.9 \\
\hline \multirow[t]{2}{*}{ Nag and Rakov (2014) [9] (overall) } & 45 (summer) & 7.5 & - & 6.8 \\
\hline & 17 (winter) & 8.5 & - & 7.4 \\
\hline This study & 48 & 22.4 & 28.1 & 12.9 \\
\hline \multicolumn{5}{|c|}{$10-90 \%$ rise time, $\mu \mathrm{s}$} \\
\hline Beasley et al. (1983) [37] & 6 & 2.7 & - & - \\
\hline \multirow[t]{2}{*}{ Hojo et al. (1985) [38] } & 32 (winter) & 8.7 & - & - \\
\hline & 44 (summer) & 6.7 & - & - \\
\hline \multirow[t]{2}{*}{ Cooray (1986) [39] } & 15 & 6.2 & 1.4 & - \\
\hline & 62 & 4 & 2.1 & 3.4 \\
\hline \multirow[t]{2}{*}{ Nag and Rakov (2014) [9] (overall) } & 45 (summer) & 4.1 & & 3.5 \\
\hline & 17 (cold) & 3.8 & & 3.1 \\
\hline This study & 48 & 9.4 & 13.2 & 5.1 \\
\hline \multicolumn{5}{|c|}{ Slow front duration, $\mu \mathrm{s}$} \\
\hline Cooray and Lundquist (1982) [2] & 63 & 10 & 11 & - \\
\hline Cooray (1986) [39] & 20 & 8.2 & 1.7 & - \\
\hline Ishii and Hojo (1989) [40] & - & 19.3 & - & - \\
\hline Cooray et al. (2004) [25] & 63 & 8.3 & 2.6 & - \\
\hline Nag and Rakov (2014) [9] (overall) & 62 & 5.9 & 3.6 & 5 \\
\hline This study & 48 & 19.1 & 25.7 & 9.8 \\
\hline \multicolumn{5}{|c|}{ Slow front amplitude relative to peak, $\%$} \\
\hline \multirow[t]{2}{*}{ Cooray and Lundquist (1982) [2] } & 67 & 38 & 11 & - \\
\hline & 31 & 44 & 14 & - \\
\hline Cooray (1986) [39] & 20 & 45 & 7 & - \\
\hline Cooray et al. (2004) [25] & 63 & 61 & 0.7 & - \\
\hline Nag and Rakov (2014) [9] (overall) & 62 & 39 & 15 & 37 \\
\hline This study & 48 & 44.3 & 15 & 41.7 \\
\hline \multicolumn{5}{|c|}{ Fast transition rise time $(10-90 \%), \mu \mathrm{s}$} \\
\hline Cooray (1986) [39] & 20 & 0.56 & 0.7 & - \\
\hline Ishii and Hojo (1989) [40] & 24 & 0.11 & 0.62 & - \\
\hline Cooray et al. (2004) [25] & 63 & 0.26 & 0.11 & - \\
\hline Nag and Rakov (2014) [9] (overall) & 62 & 1.2 & 0.77 & 1 \\
\hline This study & 48 & 2.6 & 4.3 & 1.6 \\
\hline \multicolumn{5}{|c|}{ Zero-crossing time, $\mu \mathrm{s}$} \\
\hline \multirow[t]{2}{*}{ Ishii and Hojo (1989) [40] } & 34 & 151 & - & - \\
\hline & 89 & 93 & - & - \\
\hline \multirow[t]{2}{*}{ Nag and Rakov (2014) [9] (overall) } & 42 (winter) & 69 & 92 & 45 \\
\hline & 10 (summer) & 53 & - & - \\
\hline This study & 48 & 57.8 & 140.3 & 23.4 \\
\hline
\end{tabular}


TABLe 7: Continued.

\begin{tabular}{|c|c|c|c|c|}
\hline & Sample size, $N$ & $\mathrm{AM}$ & SD & GM \\
\hline \multicolumn{5}{|c|}{ Opposite polarity overshoot relative to peak, \% } \\
\hline \multirow{2}{*}{ Ishii and Hojo (1989) [40] } & 34 (summer) & 24 & - & - \\
\hline & 89 (winter) & 40 & - & - \\
\hline Nag and Rakov (2014) [9] & 33 & 15 & 9.3 & 13 \\
\hline This study & 41 & 44.8 & 27.2 & 35.3 \\
\hline
\end{tabular}

TABLE 8: Comparative values of key parameters in per unit (values measured in Malaysia are made as bases).

\begin{tabular}{|c|c|c|c|c|c|c|}
\hline \multirow{3}{*}{ Parameters } & \multirow{2}{*}{ Tropic } & \multirow{2}{*}{ Subtropic } & \multicolumn{4}{|c|}{ Temperate } \\
\hline & & & Sweden & & Japan & \\
\hline & Malaysia (48 samples) & Florida (62 samples) & Number of Samples & & Number of Samples & \\
\hline Zero-to-peak rise time & 1 & 0.3 & 64 & 0.6 & (Summer 32) & 0.6 \\
\hline $10-90 \%$ rise time & 1 & 0.4 & 15 & 0.7 & (Summer 32) & 0.7 \\
\hline Slow front duration & 1 & 0.3 & 63 & 0.4 & (Summer 32) & 0.7 \\
\hline $\begin{array}{l}\text { Slow front amplitude relative to } \\
\text { peak }\end{array}$ & 1 & 0.9 & 63 & 1.4 & - & - \\
\hline $\begin{array}{l}\text { Fast transition rise time } \\
(10-90 \%)\end{array}$ & 1 & 0.4 & 63 & 0.1 & (Overall 24) & 0.04 \\
\hline Zero-crossing time & 1 & 0.9 & - & - & (Summer 34) & 2.6 \\
\hline $\begin{array}{l}\text { Opposite polarity overshoot } \\
\text { relative to peak }\end{array}$ & 1 & 0.3 & - & - & (Summer 34) & 0.5 \\
\hline
\end{tabular}

fast transition rise time (10-90\%) found in this study (1 p.u.) is much larger when compared with those from Florida (0.4 p.u.), Sweden (0.1 p.u.), and Japan (0.04 p.u.). The higher slow front duration and fast transition rise time (10-90\%) observed in Malaysia may probably be due to either the different climatic condition, or the field propagation effect over finitely conducting soil.

\subsection{Zero-Crossing Time and Opposite Polarity Overshoot} Relative to Peak. In this study, the average zero-crossing and opposite polarity overshoot relative to peak lie within a range of 50-90 $\mu$ s and 10-40\% [41], respectively. The average of zero-crossing time measured is $57.8 \mu \mathrm{s}$, which is slightly higher than that measured in Florida (in summer). However, the value measured by Ishii and Hojo [40] during the summer thunderstorm in Japan is 2.6 times larger than the zerocrossing time in this study. This difference may probably be due to the climate dependent height of thundercloud base [16]. Furthermore, the opposite polarity overshoot relative to peak obtained in this study is at least two times larger than those from other studies.

5.4. Overall Comparison. There is a similarity of results obtained from different countries having the same climatic condition. For example, the zero-to-peak and 10-90\% rise time obtained in Sweden are almost the same as those in Japan. For the purpose of climatic condition comparison, the data from Japan and Sweden are grouped under temperate condition with equivalent average values.

Three climatic conditions were identified. These are tropic, subtropic, and temperate. In tropical climate, all positive lightning parameters are generally higher than those in the subtropical and temperate conditions, except for the slow front amplitude relative to peak and the zero-crossing time. In temperate climate, all positive lightning parameters are higher than those in the subtropical condition, except for the fast transition rise time (10-90\%).

It is suggested that the differences in some characteristics of positive lightning are probably due to the effects of differences in climate, geographical location, and height of the thundercloud base $[37,42]$.

\section{Conclusion}

Various parameters of positive return stroke electric field were examined using data acquired in Johor, Malaysia, during a period in 2012. There were a total of 48 return strokes in 41 positive flashes. A total of $12 \%$ of the recorded positive lightning are multiple stroke flashes with an average multiplicity of 1.2 strokes per flash. It can be noted that majority of positive lightning in this study are initiated from the primary positive charge rather than as a by-product of in-cloud discharges. It is also noted that the magnitude of the opposite polarity overshoot relative to peak can somehow indirectly indicate the distance of the return stroke from the measuring sensor. A comparison of various positive return stroke electric field parameters obtained from different studies including this study is presented in Table 7. An attempt is made to compare the parameters according to the climatic region as given in Table 8.

There is a similarity of results obtained from different countries having the same climatic condition. In tropical climate, all positive lightning parameters are generally higher than those in the subtropical and temperate conditions, 
except for the slow front amplitude relative to peak and the zero-crossing time. In temperate climate, all positive lightning parameters are higher than those in the subtropical condition, except for the fast transition rise time. Therefore it can be inferred that climatic effect contributes to different positive lightning characteristics in tropics, subtropic, and temperate regions. Further research on positive lightning is needed to determine the effect of meteorological conditions on their occurrences and characteristics, in particular using different types of sensors.

\section{Conflict of Interests}

The authors declare that there is no conflict of interests regarding the publication of this paper.

\section{Acknowledgments}

Authors wish to thank Ministry of Science, Technology and Innovation (MOSTI), Ministry of Education (MOE), and Universiti Teknologi Malaysia (Research Vote nos. 4S045, 03H59, 4F291, and 4F672) for the financial aid.

\section{References}

[1] A. Nag and V. A. Rakov, "Positive lightning: an overview, new observations, and inferences," Journal of Geophysical Research D: Atmospheres, vol. 117, no. 8, Article ID D08109, 2012.

[2] V. Cooray and S. Lundquist, "On the characteristics of some radiation fields from lightning and their possible origin in positive ground flashes," Journal of Geophysical Research: Oceans, vol. 87, pp. 11203-11214, 1982.

[3] V. A. Rakov, "A review of positive and bipolar lightning discharges," Bulletin of the American Meteorological Society, vol. 84, no. 6, pp. 767-776, 2003.

[4] C. Schumann and M. M. F. Saba, "Continuing current intensity in positive ground flashes," in Proceedings of the 31st International Conference on Lightning Protection (ICLP '12), pp. 1-5, September 2012.

[5] M. A. Uman, The Lightning Discharge, Courier Dover Publications, Mineola, NY, USA, 2012.

[6] C. Romero, F. Rachidi, M. Rubinstein, M. Paolone, V. A. Rakov, and D. Pavanello, "Positive lightning flashes recorded on the Säntis tower from May 2010 to January 2012," Journal of Geophysical Research D: Atmospheres, vol. 118, no. 23, pp. 1287912892, 2013.

[7] N. Abdullah, M. P. Yahaya, and N. S. Hudi, "Implementation and use of lightning detection network in Malaysia," in Proceedings of the IEEE 2nd International Power and Energy Conference (PECon '08), pp. 383-386, Johor Bahru, Malaysia, December 2008.

[8] N. Abdullah and N. M. Hatta, "Cloud-to-ground lightning occurrences in Peninsular Malaysia and its use in improvement of distribution line lightning performances," in Proceedings of the IEEE International Conference on Power and Energy (PECon '12), pp. 819-822, December 2012.

[9] A. Nag and V. A. Rakov, "Parameters of electric field waveforms produced by positive lightning return strokes," IEEE Transactions on Electromagnetic Compatibility, vol. 56, no. 4, pp. 932939, 2014.
[10] Z. Baharudin, V. Cooray, M. Rahman, P. Hettiarachchi, and N. A. Ahmad, On the Characteristics of Positive Lightning Ground Flashes in Sweden, Uppsala University, 2014.

[11] M. M. F. Saba, W. Schulz, T. A. Warner et al., "High-speed video observations of positive lightning flashes to ground," Journal of Geophysical Research D: Atmospheres, vol. 115, no. 24, Article ID D24201, 2010.

[12] S. A. Yashunin, E. A. Mareev, and V. A. Rakov, "Are lightning M components capable of initiating sprites and sprite halos?" Journal of Geophysical Research D: Atmospheres, vol. 112, no. 10, Article ID D10109, 2007.

[13] K. Berger, "Parameters of lightning flashes," Electra, vol. 41, pp. 23-37, 1975.

[14] Y. Goto and K. Narita, "Electrical characteristics of winter lightning," Journal of Atmospheric and Terrestrial Physics, vol. 57, no. 5, pp. 449-458, 1995.

[15] G. Diendorfer, H. Pichler, and M. Mair, "Characteristics of positive upward lightning measured on an instrumented tower," in Proceedings of the 28th International Conference on Lightning Protection, Kanazawa, Japan, September 2006.

[16] V. Cooray, An Introduction to Lightning, Springer, 2014.

[17] Z. A. Baharudin, V. Cooray, M. Rahman, P. Hettiarachchi, and N. A. Ahmad, Electric Field Changes Generated by Preliminary Breakdown Pulse for Positive Lightning Ground Flashes in Sweden, Uppsala University, 2014.

[18] N. A. Ahmad, M. Fernando, Z. A. Baharudin, V. Cooray, H. Ahmad, and Z. Abdul Malek, "Characteristics of narrow bipolar pulses observed in Malaysia," Journal of Atmospheric and SolarTerrestrial Physics, vol. 72, no. 5-6, pp. 534-540, 2010.

[19] K. Mehranzamir, B. Salimi, and Z. Abdul-Malek, "Investigation of preliminary breakdown pulses in lightning waveforms," in Proceedings of the Progress in Electromagnetics Research Symposium, pp. 1542-1546, Stockholm, Sweden, April 2013.

[20] K. Mehranzamir, B. Salimi, and Z. Abdul-Malek, "Comparative study of lightning models with lightning discharges in Malaysia," in Proceedings of the IEEE Conference on Electrical Insulation and Dielectric Phenomena (CEIDP '13), pp. 10851088, Shenzhen, China, October 2013.

[21] B. Salimi, K. Mehranzamir, and Z. Abdul-Malek, "Statistical analysis of lightning electric field measured under Malaysian condition," Asia-Pacific Journal of Atmospheric Sciences, vol. 50, no. 2, pp. 133-137, 2014.

[22] N. Azlinda Ahmad, M. Fernando, Z. A. Baharudin et al., "The first electric field pulse of cloud and cloud-to-ground lightning discharges," Journal of Atmospheric and Solar-Terrestrial Physics, vol. 72, no. 2-3, pp. 143-150, 2010.

[23] Z. A. Baharudin, Characterizations of Ground Flashes from Tropic to Northern Region, Uppsala University, 2014.

[24] V. A. Rakov, "Lightning parameters for engineering applications (keynote speech)," in Proceedings of the Asia-Pacific Symposium on Electromagnetic Compatibility (APEMC '10), pp. 1120-1123, IEEE, Beijing, China, April 2010.

[25] V. Cooray, M. Fernando, C. Gomes, and T. Sorenssen, "The fine structure of positive lightning return-stroke radiation fields," IEEE Transactions on Electromagnetic Compatibility, vol. 46, no. 1, pp. 87-95, 2004.

[26] Y. T. Lin, M. A. Uman, J. A. Tiller et al., "Characterization of lightning return stroke electric and magnetic fields from simultaneous two-station measurements," Journal of Geophysical Research, vol. 84, no. 10, pp. 6307-6314, 1979. 
[27] M. A. Haddad, V. A. Rakov, and S. A. Cummer, "New measurements of lightning electric fields in Florida: Waveform characteristics, interaction with the ionosphere, and peak current estimates," Journal of Geophysical Research D: Atmospheres, vol. 117, no. 10, Article ID D10101, 2012.

[28] K. B. Eack, "Electrical characteristics of narrow bipolar events," Geophysical Research Letters, vol. 31, no. 20, 2004.

[29] M. Paolone, F. Rachidi-Haeri, and C. A. Nucci, IEEE Guide for Improving the Lightning Performance of Electric Power Overhead Distribution Lines, IEEE, 2011.

[30] F. H. Heidler, M. Manhardt, and K. Stimper, "The slowvarying electric field of negative upward lightning initiated by the peissenberg tower, Germany," IEEE Transactions on Electromagnetic Compatibility, vol. 55, no. 2, pp. 353-361, 2013.

[31] V. A. Rakov, M. A. Uman, and R. Thottappillil, "Review of lightning properties from electric field and TV observations," Journal of Geophysical Research: Atmospheres, vol. 99, no. 5, pp. 10745-10750, 1994.

[32] V. Rakov, "Lightning phenomenology and parameters important for lightning protection," in Proceedings of the 9th International Symposium on Lightning Protection (SIPDA '07), November 2007.

[33] F. Heidler, F. Drumm, and C. Hopf, "Electric fields of positive earth flashes in near thunderstorms," in Proceedings of the 24th International Conference on Lightning Protection, pp. 42-47, Birmingham, UK, September 1998.

[34] F. Heidler and C. Hopf, "Measurement results of the electric fields in cloud-to-ground lightning in nearby Munich, Germany," IEEE Transactions on Electromagnetic Compatibility, vol. 40, no. 4, pp. 436-443, 1998.

[35] S. A. Fleenor, C. J. Biagi, K. L. Cummins, E. P. Krider, and X.-M. Shao, "Characteristics of cloud-to-ground lightning in warmseason thunderstorms in the Central Great Plains," Atmospheric Research, vol. 91, no. 2-4, pp. 333-352, 2009.

[36] W. D. Rust, D. R. MacGorman, and R. T. Arnold, "Positive cloud-to-ground lightning flashes in severe storms," Geophysical Research Letters, vol. 8, pp. 791-794, 1981.

[37] W. H. Beasley, M. A. Uman, D. M. Jordan, and C. Ganesh, "Positive cloud to ground lightning return strokes," Journal of Geophysical Research: Oceans, vol. 88, no. 13, pp. 8475-8482, 1983.

[38] J. Hojo, M. Ishii, T. Kawamura, F. Suzuki, and R. Funayama, "The fine structure in the field change produced by positive ground strokes," Journal of Geophysical Research: Atmospheres (1984-2012), vol. 90, no. 4, pp. 6139-6143, 1985.

[39] V. Cooray, "A novel method to identify the radiation fields produced by positive return strokes and their submicrosecond structure," Journal of Geophysical Research: Atmospheres, vol. 91, no. D7, pp. 7907-7911, 1986.

[40] M. Ishii and J. I. Hojo, "Statistics on fine structure of cloudto-ground lightning field waveforms," Journal of Geophysical Research: Atmospheres, vol. 94, no. 11, pp. 13-274, 1989.

[41] V. Cooray, The Lightning Flash, vol. 34, Institution of Engineering and Technology (IET), Stevenage, UK, 2003.

[42] V. Cooray and S. Lundquist, "Effects of propagation on the rise times and the initial peaks of radiation fields from return strokes," Radio Science, vol. 18, no. 3, pp. 409-415, 1983. 

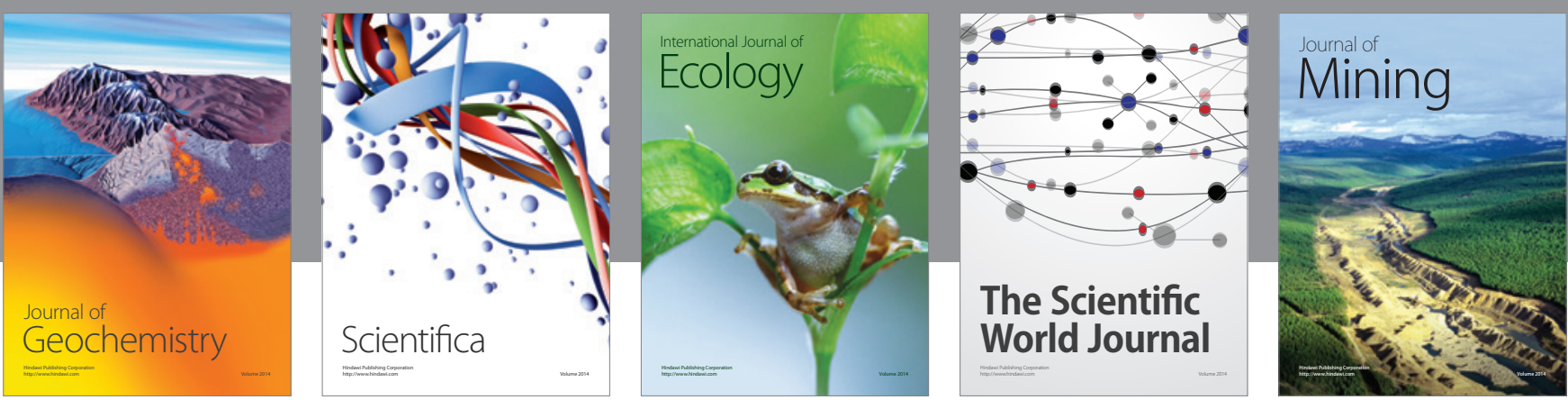

The Scientific World Journal
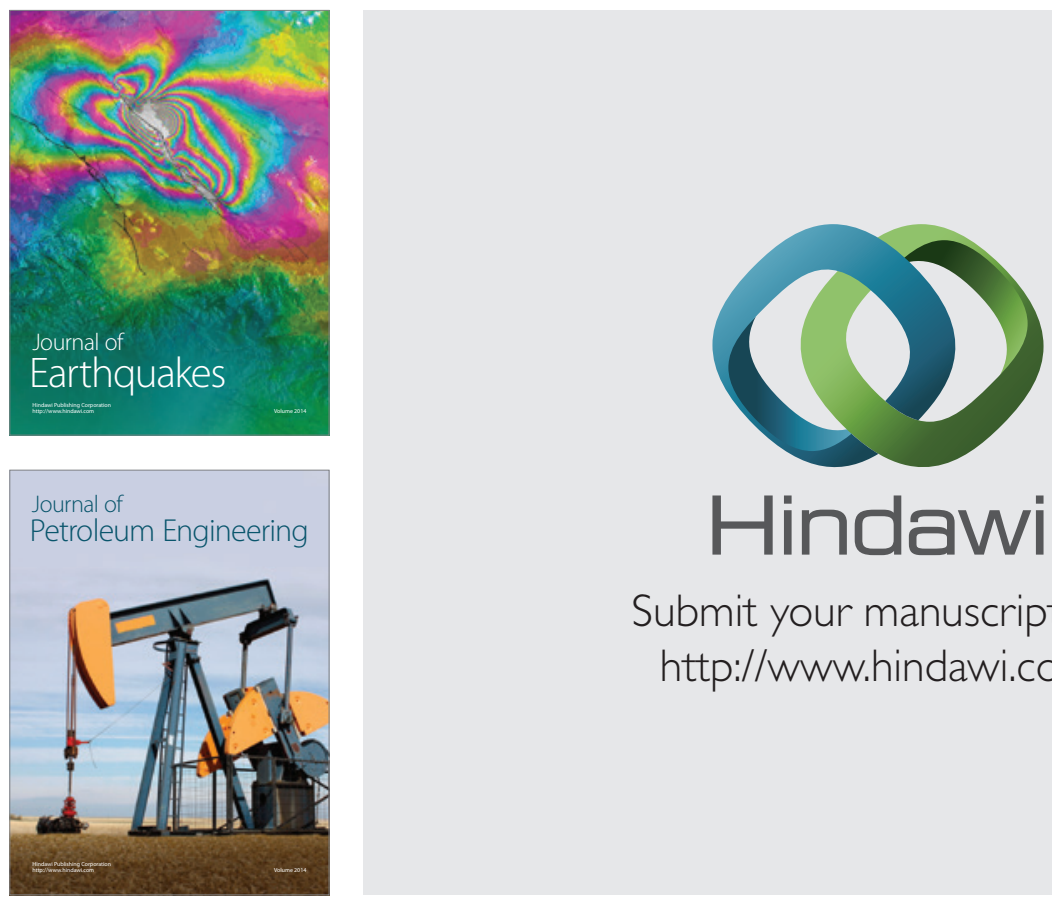

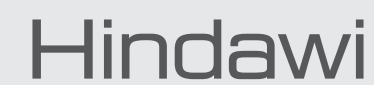

Submit your manuscripts at

http://www.hindawi.com
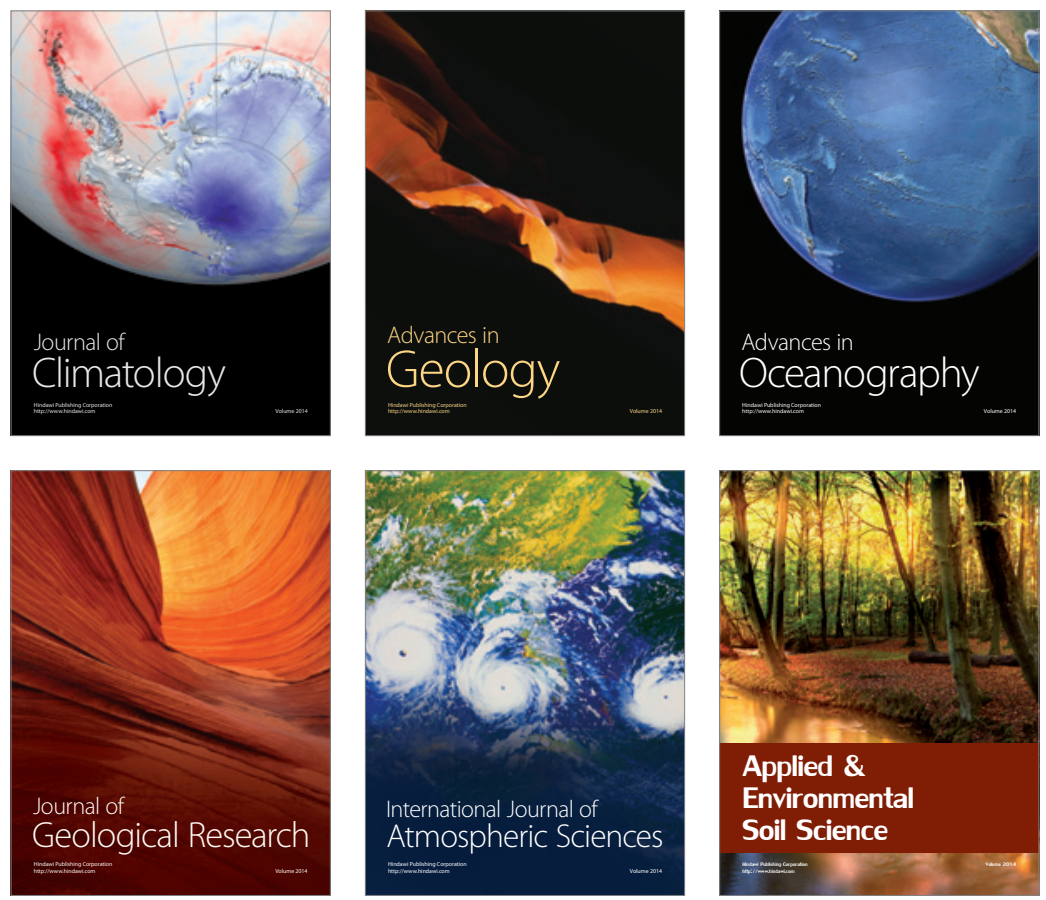
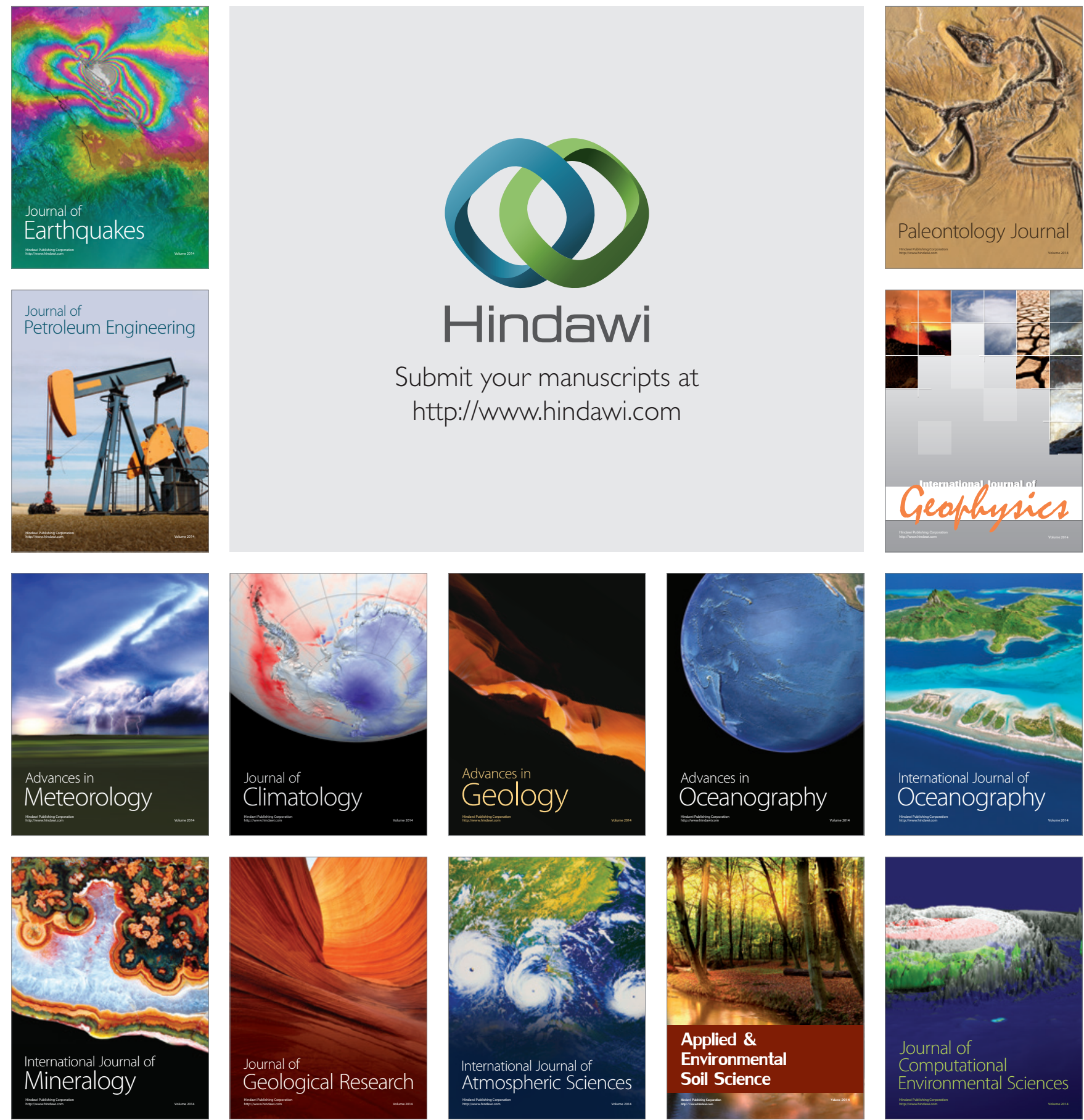